\title{
The Role of Direct-acting Antivirals in the Treatment of Children with Chronic Hepatitis C
}

\author{
Christine Hong Ting Yang ${ }^{1}$, Eric R. Yoo ${ }^{2}$ and Aijaz Ahmed*3 \\ ${ }^{1}$ Division of Pediatric Gastroenterology, Stanford University School of Medicine, Stanford, CA, USA; ${ }^{2}$ Department of Medicine, \\ University of Illinois College of Medicine, Chicago, IL, USA; ${ }^{3}$ Division of Gastroenterology and Hepatology, \\ Stanford University School of Medicine, Stanford, CA, USA
}

\begin{abstract}
In the United States, chronic infection with the hepatitis $\mathrm{C}$ virus (HCV) affects an estimated $0.1-2 \%$ of the pediatric population, who are consequently at risk for major complications, including cirrhosis, hepatocellular carcinoma, and death. The current standard of treatment for chronic hepatitis $\mathrm{C}(\mathrm{CHC})$ in children is pegylated-interferon-alpha (PEG-IFN) in combination with ribavirin. PEG-IFN/ribavirin therapy is approved for children ages 3 and older; however, it is often held from use until adulthood because of its extensive list of potential side effects and high likelihood of causing adverse symptoms. While $\mathrm{CHC}$ is usually indolent in children and adolescents, immediately treating and curbing the spread of $\mathrm{HCV}$ before adulthood is important, as there can be transmission to other individuals via sexual activity and infected females can later vertically transmit the infection during pregnancy, the latter representing the most common means of transmission for children in the United States. The recent development of direct-acting antivirals has shown promising results in clinical trials for use in children and has dramatically increased the rates of sustained virological response in adults while improving side effect profiles as compared to interferonbased treatments. Given the usually indolent course of $\mathrm{CHC}$ in children, significant side effects of the currently-approved PEG-IFN/ribavirin therapy, and likely availability of all-oral interferon-free regimens for children within a few years, deferring treatment in clinically-stable children with $\mathrm{CHC}$ in anticipation of upcoming superior treatment modalities may be justified.
\end{abstract}

Citation of this article: Yang $\mathrm{CHT}$, Yoo ER, Ahmed A. The role of direct-acting antivirals in the treatment of children with chronic hepatitis C. J Clin Transl Hepatol 2017;5(1):59-66. doi: $10.14218 / \mathrm{JCTH} .2016 .00053$.

Keywords: Hepatitis C virus; Chronic hepatitis C; Pediatric; Children; Anti-viral therapy.

Abbreviations: $\mathrm{HCV}$, hepatitis $\mathrm{C}$ virus; $\mathrm{CHC}$, chronic HCV infection; US, United States; HIV, human immunodeficiency virus; FDA, Food and Drug Administration; PEG-IFN, pegylated-interferon-alpha; SVR, sustained virological response; ETR, end-of-treatment response; PO, per os; EVR, early virological response; RVR, rapid virological response; SNP, single nucleotide polymorphism; IL-28B, interleukin 28B; DAAs, direct-acting antiviral agents; TN, treatment-naïve; TE, treatment experienced; RAV, resistance-associated variant; SVR-12, sustained virological response at 12 weeks; BMI, body mass index.

Received: 24 October 2016; Revised: 13 December 2016; Accepted: 05 January 2017

*Correspondence to: Aijaz Ahmed, Division of Gastroenterology and Hepatology, Stanford University School of Medicine, 750 Welch Road, Suite \#210, Stanford, CA 94304, USA. Tel: +1-650-498-5691, Fax: +1-650-498-5692, E-mail: aijazahmed@ stanford.edu

\section{Introduction}

Hepatitis C virus (HCV) is an RNA virus which affects $>180$ million people worldwide, ${ }^{1}$ with global seroprevalence of antibodies to HCV increasing from $2.3 \%$ in 1990 to $2.8 \%$ in $2005 .^{2}$ In North America, the overall prevalence of HCV antibody positivity is estimated to be about $1-1.5 \%$, with $0.17 \%$ in $6-11$ year-olds and $0.39 \%$ in $12-19$ year-olds. HCV has a high propensity for chronic infection and is the leading cause of chronic infectious hepatitis in children in industrialized countries. ${ }^{3}$ Depending on population and risk factors, chronic HCV infection $(\mathrm{CHC})$ is estimated to affect $0.1-2 \%$ of children in the United States (US). ${ }^{4} \mathrm{CHC}$ is defined as evidence of active viral infection with detectable HCV RNA for at least 6 months, with the implication of ongoing liver injury. ${ }^{1}$ In the US, this translates to $\mathrm{CHC}$ afflicting $23,000-46,000$ children, ${ }^{5}$ who are subsequently at risk for its complications, including cirrhosis, liver cancer, and death. ${ }^{6}$

\section{Virology}

$\mathrm{HCV}$ is a single-stranded, positive-sense RNA virus belonging to the Flaviviridae family and hepacivirus genus. There are six genotypes, numbered $1-6$, with 100 subtypes, denoted by lower-case letters. ${ }^{7}$ Predominance of genotypes vary geographically, with the most common (genotype 1) having worldwide distribution but predominance in North America (HCV 1a) and Europe (HCV 1b). Genotypes 2 and 3 also have worldwide distributions, while genotype 4 is predominantly in North Africa and the Middle East, genotype 5 is in South Africa, and genotype 6 is in Asia. ${ }^{3}$ The specific genotype of the virus has important implications for treatment, as genotypes 1 and 4 are more difficult to cure with interferon (IFN)-containing regimens as compared to genotypes 2 and 3 , though overall genotype 3 is considered the most challenging to treat. ${ }^{8}$ Furthermore, the viral RNA polymerase is highly error prone, leading to the rapid development of multiple 'quasispecies' within a single individual. It is speculated that these quasispecies, and their interactions with their host, may explain the variability in the clinical course of the disease among individuals infected with $\mathrm{HCV}^{7,9}$

\section{Natural history of HCV in children}

The transmission of $\mathrm{HCV}$ requires blood contact, and the means of transmission include blood, blood products, organ transplantation, tissue penetration with infected objects (such as contaminated needles and tattooing instruments), sexual 
contact, and vertical transmission from mother to child. Prior to the implementation of rigorous screening measures in 1992, most children acquired HCV from blood, blood products, or organ transplantation. Since 1992, by far the most common means of transmission has become vertical transmission, ${ }^{10}$ and in the US, there are an estimated 7,500 new cases annually from vertical transmission. ${ }^{11}$

Vertical transmission occurs in $5-10 \%$ of at-risk pregnancies, ${ }^{12,13}$ and factors which increase the risk of transmission include concomitant maternal human immunodeficiency virus (HIV) infection, high maternal HCV viral load $(>600,000$ $\mathrm{IU} / \mathrm{mL}$ ), internal monitoring of the fetus, prolonged rupture of membranes, and fetal anoxia around time of delivery. ${ }^{1}$ Spontaneous resolution of infection can occur in early infancy, with $25-40 \%$ of infected infants clearing the infection. This phenomenon can occur in older children as well, but has been reported at far lower rates of $6-12 \%$. Spontaneous resolution has been observed in children up to 7-8 years of age, but is much rarer after age $3 .^{6}$ The majority of children (54-86\%) will go on to develop $\mathrm{CHC}^{3}$

The clinical course of $\mathrm{CHC}$ acquired in childhood appears to be mild: most children are asymptomatic, there is no effect on growth, ${ }^{14}$ histopathological changes usually only show minimal inflammation, ${ }^{15}$ and hepatocellular carcinoma is rare, with two cases having been documented. ${ }^{16}$ On the other hand, adolescents who become infected follow the adult pattern of disease. ${ }^{2}$ However, $\mathrm{CHC}$ is considered a progressive disease with accumulating liver damage: ${ }^{17}$ there is a 26 -fold increase in risk of liver-related death associated with $\mathrm{CHC}$ acquired in childhood; ${ }^{11}$ bridging fibrosis is reportedly present in $12 \%$ of children; ${ }^{18}$ cirrhosis is present in $1-2 \%$ of children; decompensated cirrhosis has been documented in children between the ages of 4-11; and liver transplantation may be necessary for end-stage liver disease secondary to $\mathrm{CHC} .{ }^{16}$ Furthermore, hepatocellular carcinoma has been reported in adults with $\mathrm{CHC}$ in the absence of cirrhosis. ${ }^{19}$

The 10-year costs associated with pediatric HCV infection are estimated to be \$199-336 million. ${ }^{5}$ Furthermore, children with $\mathrm{CHC}$ experience impaired quality of life due to multiple factors, including developmental delay, learning disorders, and cognitive deficits less severe than those of attention deficit hyperactivity disorder, but still indicative of decreased executive function. ${ }^{20}$

\section{Current treatment for children with $\mathrm{CHC}$}

Currently, the only US Food and Drug Administration (FDA)approved therapy for $\mathrm{CHC}$ in children ages 3 and older is pegylated-interferon-alpha (PEG-IFN) in combination with ribavirin. ${ }^{21}$ IFN is a cytokine that induces multiple IFN-stimulated genes, including double-stranded RNAses, inhibitors of viral protein translation, and proteins which destabilize viral messenger HCV RNA. The expression of these genes under the influence of IFN also results in the activation of natural killer cells, maturation of dendritic cells, proliferation of memory T cells, and prevention of T cell apoptosis. ${ }^{22}$ The pegylation of IFN to large molecule polyethylene glycol results in a longer half-life, better pharmacokinetic profile, and better rate of virological response. ${ }^{23,24}$ Ribavirin is a synthetic guanosine analogue that interferes with the synthesis of guanosine triphosphate, inhibiting the viral capping of mRNA as well as the viral RNA polymerase. ${ }^{25}$ The addition of ribavirin to PEG-IFN improved sustained virological response (SVR) up to $30-40 \%$, along with end-of-treatment response (ETR), in adults and children, ${ }^{26}$ as well as significantly decreased the relapse rate of $\mathrm{HCV}$ infection. ${ }^{27,28}$

There are two formulations of PEG-IFN which are FDAapproved for use in children with CHC. PEG-IFN-2b is dosed at $60 \mathrm{~g} / \mathrm{m}^{2} /$ week, while PEG-IFN-2a is dosed at $180 \mathrm{~g} / 1.73$ $\mathrm{m}^{2} /$ week. Both options are delivered subcutaneously once weekly, and neither has been consistently demonstrated to have superiority over the other. Concurrently, children should receive ribavirin, dosed at $15 \mathrm{mg} / \mathrm{kg} /$ day per os (PO) divided twice daily. Duration of therapy depends on HCV genotype, with 48 weeks of therapy for genotypes 1 and 4, and 24 weeks for genotypes 2 and $3 .{ }^{1}$ The efficacy of this treatment regimen also varies by genotype; a meta-analysis of 8 trials evaluating the efficacy of PEG-IFN with ribavirin found children with genotypes 1 and 4 achieved early virological response (EVR) and SVR $61 \%$ and $52 \%$ of the time, respectively. This is in contrast to children with genotypes 2 and 3, who achieved EVR and SVR $87 \%$ and $89 \%$ of the time, respectively. Overall, SVR was achieved in $58 \%$ of children, with relapse rate of $7 \%$, and $15 \%$ of children not showing virologic response to therapy. ${ }^{29}$

In adults receiving PEG-IFN with ribavirin, rapid virological response (RVR) has been identified as the best predictor of SVR, and viral load $<600,000 \mathrm{IU} / \mathrm{mL}$ has been found to be a positive predictor for SVR in adults with HCV genotype $1 .{ }^{30}$ Single nucleotide polymorphisms (SNPs) around the gene for interleukin 28B (IL-28B) have been associated with different treatment results in adults, ${ }^{31}$ and preliminary studies in children may confirm a similar result in children. Specifically, IL-28B rs12979860 CC and rs8099917 TT may be associated with higher rates of SVR in children with genotypes 1 and 4 who are treated with PEG-IFN and ribavirin. ${ }^{32}$ Otherwise, other predictors of SVR in adults, including younger age, baseline aminotransferase levels, sex, previous treatments, and liver histology, have not been confirmed in children. ${ }^{30}$

While discontinuation of therapy due to adverse events is low at $4 \%$, adverse events occur in almost all children undergoing treatment with PEG-IFN and ribavirin. ${ }^{29}$ PEG-IFN almost universally causes constitutional symptoms, including fever, fatigue, myalgia, arthralgia, headache, nausea, and other nonspecific gastrointestinal complaints. ${ }^{33}$ One-third of children experience bone marrow suppression (neutropenia, thrombocytopenia), as well as neuropsychiatric complications (irritability, depression, and rarely suicidal ideation). ${ }^{26}$ PEGIFN can also cause hypothyroidism, ${ }^{34}$ ophthalmological complications, ${ }^{35}$ and injection site reactions. ${ }^{36}$ Ribavirin can cause hemolytic anemia ${ }^{34}$ and rash. ${ }^{36}$ Furthermore, both medications are considered teratogenic. ${ }^{37}$ Weight loss and inhibited growth are also seen; however, most children will have compensatory weight and height gain after completion of therapy. ${ }^{30}$

\section{New therapy for $\mathrm{CHC}$ in adults}

In adults, PEG-IFN and ribavirin have been supplanted by newer therapies; specifically, small molecules known as direct-acting antivirals (DAAs) have been developed which target viral enzymes responsible for various parts of the HCV life cycle. The HCV genome encodes a single precursor polyprotein that is processed by host signal peptidases and HCV proteases into two classes of proteins: structural (core, envelope E1,E2/p7) and non-structural (NS2: protease, NS3: protease, NS4A: cofactor for NS3, NS5A: creates changes in the cellular membrane allowing for viral replication, NS5B: RNA polymerase). ${ }^{38,39}$ DAAs target non-structural proteins, 
and the current DAAs in clinical use have been classified as NS3/4A protease inhibitors, NS5A inhibitors, and NS5B polymerase inhibitors (Table 1 ).

NS3/4A protease inhibitors interfere with HCV polyprotein processing by targeting the shallow enzymatic groove of the HCV protease. ${ }^{40}$ The addition of NS3/4A protease inhibitors to the traditional PEG-IFN/ribavirin therapy resulted in increased SVR rates, up to $70-80 \%$ in treatment-naïve (TN) HCV genotype 1 patients. ${ }^{41,42}$ Unfortunately, there is a low barrier to resistance with NS3/4A protease inhibitors, ${ }^{43}$ as well as severe side effects. Newer NS3/4A inhibitors (including grazoprevir, simeprevir, and paritaprevir which is given with ritonavir, an HIV protease inhibitor which inhibits cytochrome P3A4 to boost paritaprevir's activity), have broader genotype activity as well as improved tolerability and resistance profiles. ${ }^{6}$ The newest NS3/4A protease inhibitor is grazoprevir, which is administered in conjunction with the NS5A inhibitor elbasvir, with or without ribavirin, and is an approved therapy for HCV genotypes 1 and $4 .{ }^{44}$

NS5A is an RNA-binding protein involved in modulating the cellular environment by interacting with other non-structural proteins, and is required for viral assembly. ${ }^{45,46}$ NS5A inhibitor monotherapy results in rapid HCV RNA decline, but also rapid development of resistance; ${ }^{47}$ thus, it is used in combination with other agents. ${ }^{48}$ In addition, $10-15 \%$ of HCV genotype 1 -infected patients will have NS5A resistance-associated variants (RAVs) at baseline, which can decrease NS5A activity by greater than 5 -fold. NS5A-containing regimens can still be utilized in these patients, but with the addition of weightbased ribavirin. ${ }^{44}$ The newest approved NS5A inhibitors
Table 1. Currently approved direct-acting antiviral agents

\begin{tabular}{ll}
\hline NS3 protease inhibitors & $\begin{array}{l}\text { None currently available } \\
\text { NS3/4A protease inhibitors }\end{array}$ \\
& $\begin{array}{l}\text { Paritaprevir } \\
\text { Simeprevir }\end{array}$ \\
NS5A inhibitors & $\begin{array}{l}\text { Daclatasvir } \\
\text { Elbasvir } \\
\text { Ledipasvir } \\
\text { Ombitasvir } \\
\text { Velpatasvir }\end{array}$ \\
& Dasabuvir \\
NS5B non-nucleoside & Sofosbuvir \\
polymerase inhibitors & \\
polymerase inhibitors & \\
\hline
\end{tabular}

include elbasvir, given with NS3/4 protease inhibitor grazoprevir, as well as velpatasvir, given with the NS5B nucleoside analogue inhibitor sofosbuvir. The latter is the first approved all-oral pan-genotypic HCV treatment regimen in the US. ${ }^{49}$

NS5B inhibitors interfere with viral replication by binding the NS5B RNA-dependent RNA polymerase. ${ }^{25}$ They are classified as nucleoside analogue inhibitors (which are incorporated into the RNA chain and thus cause chain termination) or nonnucleoside inhibitors (which act on various allosteric sites to induce conformational change in the RNA polymerase).$^{50}$ NS5B non-nucleoside inhibitors have good efficacy in reduction of HCV RNA levels and have mild, well-tolerated side effects.

Table 2. Treatment options for adults with CHC without cirrhosis (listed by evidence then alphabetically)

\begin{tabular}{|c|c|c|}
\hline Genotype & Recommended & Alternative \\
\hline $1 \mathrm{a}$ & $\begin{array}{l}\text { Elbasvir/grazoprevir } \times 12 \text { weeks (if no NS5A RAVs) (Class I, } \\
\text { Level A) } \\
\text { Ledipasvir/sofosbuvir } \times 12 \text { weeks (Class I, Level A) } \\
\text { Paritaprevir/ritonavir/ombitasvir with dasabuvir and ribavirin } \times \\
12 \text { weeks (Class I, Level A) } \\
\text { Simeprevir with sofosbuvir } \times 12 \text { weeks (Class I, Level A) } \\
\text { Sofosbuvir/velpatasvir } \times 12 \text { weeks (Class I, Level A) } \\
\text { Daclatasvir with sofosbuvir } \times 12 \text { weeks (Class I, Level B) }\end{array}$ & $\begin{array}{l}\text { Elbasvir/grazoprevir with ribavirin } \times 16 \text { weeks } \\
\text { (if NS5A RAVs detected) (Class IIa, Level B) }\end{array}$ \\
\hline $1 b$ & $\begin{array}{l}\text { Elbasvir/grazoprevir with ribavirin } \times 12 \text { weeks }(\text { Class I, Level A) } \\
\text { Ledipasvir/sofosbuvir } \times 12 \text { weeks (Class I, Level A) } \\
\text { Paritaprevir/ritonavir/ombitasvir with dasabuvir and ribavirin } \times \\
12 \text { weeks (Class I, Level A) } \\
\text { Simeprevir with sofosbuvir } \times 12 \text { weeks (Class I, Level A) } \\
\text { Sofosbuvir/velpatasvir } \times 12 \text { weeks (Class I, Level A) } \\
\text { Daclatasvir with sofosbuvir } \times 12 \text { weeks (Class I, Level B) }\end{array}$ & $\mathrm{N} / \mathrm{A}$ \\
\hline 2 & Sofosbuvir/velpatasvir × 12 weeks (Class I, Level A) & $\begin{array}{l}\text { Daclatasvir with sofosbuvir } \times 12 \text { weeks } \\
\text { (Class IIa, Level B) }\end{array}$ \\
\hline 3 & $\begin{array}{l}\text { Daclatasvir with sofosbuvir } \times 12 \text { weeks }(\text { Class I, Level A) } \\
\text { Sofosbuvir/velpatasvir } \times 12 \text { weeks }(\text { Class I, Level A) }\end{array}$ & $\mathrm{N} / \mathrm{A}$ \\
\hline 4 & $\begin{array}{l}\text { Paritaprevir/ritonavir/ombitasvir with dasabuvir and ribavirin } \times \\
12 \text { weeks (Class I, Level A) } \\
\text { Sofosbuvir/velpatasvir } \times 12 \text { weeks (Class I, Level A) } \\
\text { Elbasvir/grazoprevir } \times 12 \text { weeks (Class IIa, Level B) } \\
\text { Ledipasvir/sofosbuvir } \times 12 \text { weeks (Class IIa, Level B) }\end{array}$ & $\mathrm{N} / \mathrm{A}$ \\
\hline $5 / 6$ & $\begin{array}{l}\text { Sofosbuvir/velpatasvir } \times 12 \text { weeks }(\text { Class I, Level A) } \\
\text { Ledipasvir/sofosbuvir } \times 12 \text { weeks }(\text { Class IIa, Level B) }\end{array}$ & $\mathrm{N} / \mathrm{A}$ \\
\hline
\end{tabular}

Abbreviation: RAV, resistance-associated variant. 
Unfortunately, they also have a low barrier to resistance and high frequency of viral breakthrough when given as monotherapy, ${ }^{51,52}$ and do not have broad genotype activity. ${ }^{53}$ However, they can be effective in combination with other classes of DAAs.

NS5B nucleoside analogue inhibitors have broad genotype activity, as they target a highly conserved region among genotypes. They also have a high barrier to resistance, as mutations in the viral RNA polymerase lead to loss of function and impaired viral replication, and have fewer drug interactions compared to protease inhibitors. ${ }^{25}$ Sofosbuvir was the first available NS5B nucleoside analogue inhibitor. ${ }^{54}$ The current recommendations for treatment of adults with $\mathrm{CHC}$ are summarized in Tables 2-4.44,55

Some of the newest DAAs under investigation include voxilaprevir (NS3/4A protease inhibitor given with sofosbuvir and velpatasvir), glecaprevir (NS3/4A protease inhibitor) given with pibrentasvir (NS5A inhibitor), and ruzasvir (NS5A inhibitor given with investigational compound MK-3682 and grazoprevir). After the completion of four international Phase 3 trials, the combination of voxilaprevir with sofosbuvir and velpatasvir resulted in 95-97\% achieving SVR at 12 weeks after treatment (SVR-12) in patients across all genotypes, and included patients who had failed other DAAs. ${ }^{56-59}$ Glecaprevir and pibrentasvir resulted in high rates of SVR across all genotypes in five Phase 3 trials, including in patients with chronic kidney disease. ${ }^{60-65}$ Lastly, ruzasvir with MK-3682 and grazoprevir also resulted in high rates of SVR-12 in patients with $\mathrm{HCV}$ genotypes $1-3$ in Phase 2 trials. ${ }^{66-68}$
Yang C.H.T. et al: Therapies for chronic hepatitis $\mathrm{C}$ in children

\section{Future therapies for $\mathrm{CHC}$ in children}

There are case reports discussing isolated usage of DAAs in the pediatric population. Sofosbuvir and simeprevir have been used in two patients, one with a stem cell transplant and one with an umbilical cord blood transplant. The first patient was a 13 year-old boy with HCV genotype 4c who underwent stem cell transplant for sickle cell disease, and thereafter his HCV RNA levels increased to $10-50$ million $\mathrm{IU} / \mathrm{mL}$. He was treated with $400 \mathrm{mg}$ of sofosbuvir and $150 \mathrm{mg}$ of simeprevir once daily for 12 weeks, with HCV RNA becoming negative at the end of treatment, as well as at 11 and 21 weeks thereafter. ${ }^{69}$ The second patient was a 4 year-old girl with HCV genotype 1 a who underwent umbilical cord transplant for acute lymphoblastic leukemia. Upon immune recovery, she developed symptoms of acute hepatitis and was treated with $200 \mathrm{mg}$ of sofosbuvir and $75 \mathrm{mg}$ of simeprevir for 24 weeks. Her HCV viral loads have been tracked for 1.5 years and remain negative. ${ }^{70}$ Lastly, ledipasvir/sofosbuvir has been used in an adolescent female with decompensated cirrhosis secondary to HCV genotype 1a, with HCV RNA being undetectable 4 months after initiation of treatment. ${ }^{71}$

Given the success of DAAs in treating adults with $\mathrm{CHC}$, there are now multiple clinical trials evaluating DAA use in children. Thus far, two have been completed, and three are ongoing. One of the completed trials was a Phase $1 / 2$ openlabel trial examining telaprevir in combination with PEG-IFN and ribavirin in children with $\mathrm{CHC}$ secondary to HCV genotype 1 (Vertex Pharmaceuticals, clinicaltrials.gov, NCT01701063).

Table 3. Treatment options for adults with $\mathrm{CHC}$ with compensated cirrhosis (listed by evidence then alphabetically)

\begin{tabular}{|c|c|c|}
\hline Genotype & Recommended & Alternative \\
\hline $1 a$ & $\begin{array}{l}\text { Elbasvir/grazoprevir } \times 12 \text { weeks (if no NS5A RAVs) } \\
\text { (Class I, Level A) } \\
\text { Ledipasvir/sofosbuvir } \times 12 \text { weeks (Class I, Level A) } \\
\text { Sofosbuvir/velpatasvir } \times 12 \text { weeks (Class I, Level A) }\end{array}$ & $\begin{array}{l}\text { Paritaprevir/ritonavir/ombitasvir with dasabuvir and } \\
\text { ribavirin } \times 24 \text { weeks (Class I, Level A) } \\
\text { Simeprevir with sofosbuvir with or without ribavirin } \times \\
24 \text { weeks (if no Q80K polymorphism; Q80k reduces } \\
\text { simeprevir efficacy) (Class II, Level B) } \\
\text { Daclatasvir with sofosbuvir with or without ribavirin } \times \\
24 \text { weeks (Class IIa, Level B) } \\
\text { Elbasvir/grazoprevir with ribavirin } \times 16 \text { weeks (if } \\
\text { NS5A RAVs detected) (Class IIa, Level B) }\end{array}$ \\
\hline $1 b$ & $\begin{array}{l}\text { Elbasvir/grazoprevir } \times 12 \text { weeks (Class I, Level A) } \\
\text { Ledipasvir/sofosbuvir } \times 12 \text { weeks (Class I, Level A) } \\
\text { Paritaprevir/ritonavir/ombitasvir with dasabuvir } \times \\
12 \text { weeks (Class I, Level A) } \\
\text { Sofosbuvir/velpatasvir } \times 12 \text { weeks (Class I, Level A) }\end{array}$ & $\begin{array}{l}\text { Daclatasvir with sofosbuvir with or without ribavirin } \times \\
24 \text { weeks (Class IIa, Level B) } \\
\text { Simeprevir with sofosbuvir with or without ribavirin } \times \\
24 \text { weeks (Class IIa, Level B) }\end{array}$ \\
\hline 2 & Sofosbuvir/velpatasvir $\times 12$ weeks (Class I, Level A) & $\begin{array}{l}\text { Daclatasvir with sofosbuvir } \times 16-24 \text { weeks (Class IIa, } \\
\text { Level B) }\end{array}$ \\
\hline 3 & $\begin{array}{l}\text { Sofosbuvir/velpatasvir } \times 12 \text { weeks (Class I, Level A) } \\
\text { Daclatasvir with sofosbuvir with or without ribavirin } \times \\
24 \text { weeks (Class IIa, Level B) }\end{array}$ & N/A \\
\hline 4 & $\begin{array}{l}\text { Paritaprevir/ritonavir/ombitasvir with dasabuvir and } \\
\text { ribavirin } \times 12 \text { weeks (Class I, Level A) } \\
\text { Sofosbuvir/velpatasvir } \times 12 \text { weeks (Class I, Level A) } \\
\text { Elbasvir/grazoprevir } \times 12 \text { weeks (Class IIa, Level B) } \\
\text { Ledipasvir/sofosbuvir } \times 12 \text { weeks (Class IIa, Level B) }\end{array}$ & N/A \\
\hline $5 / 6$ & $\begin{array}{l}\text { Sofosbuvir/velpatasvir } \times 12 \text { weeks (Class I, Level A) } \\
\text { Ledipasvir/sofosbuvir } \times 12 \text { weeks (Class IIa, Level B) }\end{array}$ & N/A \\
\hline
\end{tabular}

Abbreviation: RAV, resistance-associated variant. 
Yang C.H.T. et al: Therapies for chronic hepatitis C in children

Table 4. Treatment options for adults with $\mathrm{CHC}$ and decompensated cirrhosis (listed by evidence then alphabetically)

\begin{tabular}{|c|c|c|c|}
\hline Genotype & $\begin{array}{l}\text { Patients who may/may not be } \\
\text { transplantation candidates }\end{array}$ & $\begin{array}{l}\text { Patients who are } \\
\text { ribavirin ineligible }\end{array}$ & $\begin{array}{l}\text { Patients in whom prior sofosbuvir-based } \\
\text { treatment failed }\end{array}$ \\
\hline $1 / 4$ & $\begin{array}{l}\text { Ledipasvir/sofosbuvir with low dose } \\
\text { ribavirin (increase as tolerated) } \times \\
12 \text { weeks (Class I, Level A) } \\
\text { Sofosbuvir/velpatasvir with weight-based } \\
\text { ribavirin } \times 12 \text { weeks (Class I, Level A) } \\
\text { Daclatasvir with sofosbuvir and low dose } \\
\text { ribavirin (increase as tolerated) } \times \\
12 \text { weeks (Class I, Level B) }\end{array}$ & $\begin{array}{l}\text { Sofosbuvir/velpatasvir } \\
\times 24 \text { weeks (Class I, } \\
\text { Level A) } \\
\text { Daclatasvir with } \\
\text { sofosbuvir } \times 24 \text { weeks } \\
\text { (Class II, Level C) } \\
\text { Ledipasvir/sofosbuvir } \\
\times 24 \text { weeks (Class II, } \\
\text { Level C) }\end{array}$ & $\begin{array}{l}\text { Ledipasvir/sofosbuvir with low dose } \\
\text { ribavirin (increase as tolerated) } \times \\
24 \text { weeks (Class II, Level C) } \\
\text { Sofosbuvir/velpatasvir with weight- } \\
\text { based ribavirin } \times 24 \text { weeks (Class II, } \\
\text { Level C) }\end{array}$ \\
\hline $2 / 3$ & $\begin{array}{l}\text { Sofosbuvir/velpatasvir with weight-based } \\
\text { ribavirin } \times 12 \text { weeks (Class I, Level A) } \\
\text { Daclatasvir with sofosbuvir and low } \\
\text { dose ribavirin (increase as tolerated) } \times \\
12 \text { weeks (Class II, Level B) }\end{array}$ & N/A & N/A \\
\hline
\end{tabular}

Of the 42 children enrolled, $69 \%$ of children ages $12-17$, $89.5 \%$ of children ages $6-11$, and $40 \%$ of children ages 3-5 achieved SVR. This study was terminated early after the completion of the Phase 1 portion, and telaprevir was withdrawn from the US market in October 2015. Similarly, a second study evaluating boceprevir with PEG-IFN and ribavirin in children ages 3-17 with $\mathrm{CHC}$ secondary to $\mathrm{HCV}$ genotype 1 was withdrawn (Merck Sharp \& Dohme, clinicaltrials.gov, NCT01590225), as it was anticipated that newer, all-oral interferon-free regimens would replace this regimen by the time the study ended. ${ }^{6}$

Currently, there are three active, multicenter, all-oral interferon-free clinical trials examining DAA use in children. Two of these are Phase 2 trials, and one is Phase 3. The Phase 3 trial is recruiting children ages 3-17 with HCV genotypes $1 \mathrm{a}, 1 \mathrm{~b}$, and 4 , with and without compensated cirrhosis. All are treated with ombitasvir/paritaprevir+ritonavir, and those with genotypes 1 a also receive dasabuvir and ribavirin. Children with genotype $1 \mathrm{~b}$ receive dasabuvir without ribavirin, and children with genotype 4 receive ribavirin without dasabuvir. Duration of therapy will be 12 weeks, with the exception of children with genotype 1 a with cirrhosis; they will receive 24 weeks of therapy. This is a three-part study evaluating pharmacokinetics (part 1), safety/efficacy (part 2 ), and long-term follow-up (part 3). Primary outcome measures for parts 2 and 3 include percentage of participants with SVR-12, percentage who relapse after SVR, and percentage who develop new HCV infection after achieving SVR. The estimated study completion date is January 2023 (AbbVie, clinicaltrials.gov, NCT02486406).

The two Phase 2 trials are recruiting children ages 3-17, and both are being conducted by Gilead Sciences. One study is recruiting children with genotypes 2 and 3 (Gilead, clinicaltrials.gov, NCT02175758), the other genotypes 1, 3, 4, 5, 6 (Gilead, clinicaltrials.gov, NCT02249182). For the former, participants are divided into ages $3-5,6-11$, and $12-17$, with 50 children between ages 3-11 and 50 between ages 12-17. All are treated with sofosbuvir and ribavirin. Dosing is $200 \mathrm{mg}$ in ages $6-11$, which is based off of pharmacokinetic data from adults as well as from a lead-in group of patients in the 6-11 age group. ${ }^{72}$ Those in the $12-17$ year-old group received the adult dose of $400 \mathrm{mg}$ of sofosbuvir, as pharmacokinetic results from the lead-in patients in that group demonstrated comparable plasma exposure and safety profiles with adult dosing of sofosbuvir and ribavirin in adolescents as in adults. ${ }^{73}$ Completion of pharmacokinetic lead-in studies for ages 3-5 is pending. Duration of therapy is 12 weeks with genotype 2, and 24 weeks with genotype 3 . Primary outcome measures for the treatment phase is incidence of any adverse event resulting in discontinuation of study drugs, with SVR-12 as a secondary outcome measure. The estimated study completion date is April 2018, though dosing for the 12-17 age range has been completed. Thirteen patients had HCV genotype 2, while 37 had genotype 3. Among those with genotype $2,62 \%$ were male, $85 \%$ were white, mean age was 15 years, mean body mass index (BMI) was $21 \mathrm{~kg} / \mathrm{m}^{2}$ (range, $16-28 \mathrm{~kg} / \mathrm{m}^{2}$ ), mean HCV RNA was $5.9 \log _{10} \mathrm{IU} / \mathrm{mL}$, and all were TN. Among those with genotype 3,57\% were male, $92 \%$ were white, mean age was 15 years, mean BMI was $23 \mathrm{~kg} / \mathrm{m}^{2}$ (range, $16-32 \mathrm{~kg} / \mathrm{m}^{2}$ ), mean HCV RNA was 6.2 $\log _{10} \mathrm{IU} / \mathrm{mL}$, and $76 \%$ were TN. Overall SVR-12 was $98 \%$, with all 13 genotype 2 patients achieving SVR-12, and 36 out of 37 genotype 3 achieving SVR-12. No serious adverse events or treatment discontinuation occurred. Among those with genotype 2, the most common adverse events were headache $(23 \%)$, nausea $(23 \%)$, abdominal pain $(15 \%)$, and diarrhea $(15 \%)$. Among those with genotype 3 , the most common adverse events were headache (24\%), nausea (24\%), asthenia $(14 \%)$, and dizziness $(11 \%) .^{74}$

For the latter study, participants are divided into ages 3-11 and $12-17$, with 100 children in each group. All are treated with ledipasvir/sofosbuvir, and as with the other study, dosing in the younger group will be based on pharmacokinetic lead-in results, while those in the older group receive the adult dose of ledipasvir/sofosbuvir at $90 \mathrm{mg} / 400 \mathrm{mg}$. For ages 6-11, dosing has been determined to be ledipasvir/sofosbuvir at $45 \mathrm{mg} / 200 \mathrm{mg}$, with dosing for ages 3-5 to be determined. No serious adverse events occurred in children ages 6-11 during pharmacokinetic studies. ${ }^{72}$ Genotype $1,4,5$, and 6 TN participants with and without cirrhosis, along with treatmentexperienced (TE) participants without cirrhosis, will receive treatment for 12 weeks; for TE participants with cirrhosis, the duration will be 12-24 weeks, based on genotype and country location of study site. For genotype 3, only TE participants will be recruited, and all will receive ledipasvir/sofosbuvir along with ribavirin for 24 weeks. Of note genotype 3 
Yang C.H.T. et al: Therapies for chronic hepatitis $\mathrm{C}$ in children

participants will only be recruited from the United Kingdom; participants with the other genotypes will be recruited from the US, United Kingdom, Australia, and New Zealand. The primary outcome measure for the treatment phase is whether any adverse events resulted in the discontinuation of study drugs; SVR-12 is one of the secondary outcome measures. The estimated study completion date is April 2018. Pharmacokinetic data from the lead-in subjects for ages $6-11$ and $12-17$ are available, ${ }^{72,73}$ with studies for ages 3-5 pending. The adult fixed-dose of ledipasvir/sofosbuvir resulted in similar plasma exposure of ledipasvir, sofosbuvir, and GS-331007 (the inactive metabolite of sofosbuvir) in adolescents as in adults, thus the adult dose was used for this age group. ${ }^{75}$ Similarly, giving half the adult fixed-dose of ledipasvir/sofosbuvir, $45 \mathrm{mg} / 200 \mathrm{mg}$, to children ages 6-11 resulted in comparable plasma exposure of ledipasvir, sofobuvir, and GS-331007 as in adults, without any severe adverse events or laboratory abnormalities. ${ }^{72}$

Results in 100 adolescents with HCV genotype 1 treated with ledipasvir/sofosbuvir are available. ${ }^{75}$ The mean age was 15 years, $37 \%$ were male, $90 \%$ were white, mean weight was $61 \mathrm{~kg}$ (range, 33-126 kg), mean baseline HCV RNA $\log _{10} \mathrm{IU} / \mathrm{mL}$ was 6.0 (range, 4.7-7.0 $\log _{10} \mathrm{IU} / \mathrm{mL}$ ), with $55 \%$ having $\mathrm{HCV}$ RNA $>800,000 \mathrm{IU} / \mathrm{mL}, 81 \%$ with genotype $1 \mathrm{a}, 80 \%$ as TN, $1 \%$ with cirrhosis, and $84 \%$ infected via vertical transmission. Ledipasvir/sofosbuvir was well tolerated, without grade 3 or 4 adverse events (severe or life-threatening adverse events), and there was no treatment discontinuation due to adverse events. The most common reported adverse events were headache $(27 \%)$, diarrhea $(14 \%)$, fatigue $(13 \%)$, nausea $(12 \%)$, cough $(10 \%)$, and vomiting $(10 \%)$. There were 9 participants with transient grade 3-4 laboratory abnormalities, which later resolved. Furthermore, 98 out of 100 participants (78 out of 80 TN, 20 out of $20 \mathrm{TE}$ ) achieved SVR-12. The remaining two participants were lost to follow-up, but both remained HCV negative at the last visit they attended. One was negative by week 2, with last follow-up at week 4 , and the other negative by week 8 , with last follow-up at week 12 . There were no virologic failures, and the only patient with cirrhosis achieved SVR-12..$^{75}$ Quality of life indicators also significantly improved both during and after achieving SVR. ${ }^{76}$ Post-treatment follow-up to evaluate SVR at 24 weeks is ongoing. ${ }^{77}$

\section{Conclusions}

The development of DAAs has dramatically increased the rates of SVR in adults while improving the side effect profile, and clinical trials for DAA use in children have been promising. Long-term safety and efficacy data in children is needed, but given the usually indolent course of $\mathrm{CHC}$ in children, significant side effects of the currently approved PEG-IFN/ribavirin therapy, and the anticipated approval of ledipasvir/sofosbuvir and sofosbuvir with ribavirin for adolescents potentially as early as 2017, deferring treatment in clinically-stable children with $\mathrm{CHC}$ in anticipation of upcoming superior treatment modalities may be justified.

\section{Conflict of interest}

Ahmed A. is a consultant and advisory board member for AbbVie Pharmaceuticals, Gilead Sciences, and Janssen
Pharmaceutical, and has research funding/grant from Gilead Sciences. There are no conflict of interest for all other authors.

\section{Author contributions}

Study concept and design ( $C H T Y$, ERY, AA), acquisition of data ( $C H T Y, E R Y, A A)$, analysis and interpretation of data (CHTY, ERY, AA), drafting of the initial and final manuscript (CHTY, ERY, AA), critical revision of the manuscript (CHTY, ERY, AA), and study supervision (AA).

\section{References}

[1] Mack CL, Gonzalez-Peralta RP, Gupta N, Leung D, Narkewicz MR, Roberts EA, et al. NASPGHAN practice guidelines: Diagnosis and management of hepatitis $\mathrm{C}$ infection in infants, children, and adolescents. J Pediatr Gastroenterol Nutr 2012;54:838-855. doi: 10.1097/MPG.0b013e318258328d.

[2] Baker RD, Baker SS. Hepatitis $C$ in children in times of change. Curr Opin Pediatr 2015;27:624-628. doi: 10.1097/MOP.0000000000000259.

[3] El-Shabrawi MH, Kamal NM. Burden of pediatric hepatitis C. World J Gastroenterol 2013;19:7880-7888. doi: 10.3748/wjg.v19.i44.7880.

[4] Armstrong GL, Wasley A, Simard EP, McQuillan GM, Kuhnert WL, Alter MJ. The prevalence of hepatitis C virus infection in the United States, 1999 through 2002. Ann Intern Med 2006; 144:705-714.

[5] Jhaveri R, Grant W, Kauf TL, McHutchison J. The burden of hepatitis C virus infection in children: estimated direct medical costs over a 10-year period. J Pediatr 2006;148:353-358. doi: 10.1016/j.jpeds.2005.10.031.

[6] Pham YH, Rosenthal P. Chronic hepatitis C infection in children. Adv Pediatr 2016;63:173-194. doi: 10.1016/j.yapd.2016.04.019.

[7] Slowik MK, Jhaveri R. Hepatitis B and C viruses in infants and young children. Semin Pediatr Infect Dis 2005;16:296-305. doi: 10.1053/j.spid.2005.06. 009.

[8] Goossens N, Negro F. Is genotype 3 of the hepatitis $C$ virus the new villain? Hepatology 2014;59:2403-2412. doi: 10.1002/hep.26905.

[9] Wen JW, Haber BA. Maternal-fetal transmission of hepatitis C infection: what is so special about babies? J Pediatr Gastroenterol Nutr 2014;58:278-282. doi: 10.1097/MPG.0000000000000258.

[10] Serranti D, Buonsenso D, Ceccarelli M, Gargiullo L, Ranno O, Valentini P. Pediatric hepatitis $C$ infection: to treat or not to treat...what's the best for the child? Eur Rev Med Pharmacol Sci 2011;15:1057-1067.

[11] Omland LH, Krarup H, Jepsen P, Georgsen J, Harritshøj LH, Riisom K, et al. Mortality in patients with chronic and cleared hepatitis $\mathrm{C}$ viral infection: a nationwide cohort study. J Hepatol 2010;53:36-42. doi: 10.1016/j.jhep. 2010.01.033.

[12] Ohto H, Terazawa S, Sasaki N, Sasaki N, Hino K, Ishiwata C, et al. Transmission of hepatitis $C$ virus from mothers to infants. The vertical transmission of Hepatitis C Virus Collaborative Study Group. N Engl J Med 1994;330: 744-750. doi: 10.1056/NEJM199403173301103.

[13] Conte D, Fraquelli M, Prati D, Colucci A, Minola E. Prevalence and clinical course of chronic hepatitis $\mathrm{C}$ virus (HCV) infection and rate of $\mathrm{HCV}$ vertical transmission in a cohort of 15,250 pregnant women. Hepatology $2000 ; 31$ : 751-755. doi: 10.1002/hep.510310328.

[14] Garazzino S, Calitri C, Versace A, Alfarano A, Scolfaro C, Bertaina C, et al. Natural history of vertically acquired HCV infection and associated autoimmune phenomena. Eur J Pediatr 2014;173:1025-1031. doi: 10.1007/ s00431-014-2286-6.

[15] Jara P, Resti M, Hierro L, Giacchino R, Barbera C, Zancan L, et al. Chronic hepatitis $C$ virus infection in childhood: clinical patterns and evolution in 224 white children. Clin Infect Dis 2003;36:275-280. doi: 10.1086/345908.

[16] González-Peralta RP, Langham MR Jr, Andres JM, Mohan P, Colombani PM, Alford MK, et al. Hepatocellular carcinoma in 2 young adolescents with chronic hepatitis C. J Pediatr Gastroenterol Nutr 2009;48:630-635. doi: 10.1097/MPG.0b013e318170af04.

[17] Guido M, Rugge M, Jara P, Hierro L, Giacchino R, Larrauri J, et al. Chronic hepatitis $C$ in children: the pathological and clinical spectrum. Gastroenterology 1998;115:1525-1529.

[18] Rumbo C, Fawaz RL, Emre SH, Suchy FJ, Kerkar N, Morotti RA, et al. Hepatitis C in children: a quaternary referral center perspective. J Pediatr Gastroenterol Nutr 2006;43:209-216. doi: 10.1097/01.mpg.0000228117.52229.32.

[19] Madhoun MF, Fazili J, Bright BC, Bader T, Roberts DN, Bronze MS. Hepatitis C prevalence in patients with hepatocellular carcinoma without cirrhosis. Am J Med Sci 2010;339:169-173. doi: 10.1097/MAJ.0b013e3181c4af27.

[20] Rodrigue JR, Balistreri W, Haber B, Jonas MM, Mohan P, Molleston JP, et al. Impact of hepatitis $C$ virus infection on children and their caregivers: quality of life, cognitive, and emotional outcomes. J Pediatr Gastroenterol Nutr 2009;48:341-347. doi: 10.1097/MPG.0b013e318185998f. 
[21] Ghany MG, Strader DB, Thomas DL, Seeff LB; American Association for the Study of Liver Diseases. Diagnosis, management, and treatment of hepatitis C: an update. Hepatology 2009;49:1335-1374. doi: 10.1002/hep. 22759.

[22] Feld JJ, Hoofnagle JH. Mechanism of action of interferon and ribavirin in treatment of hepatitis C. Nature 2005;436:967-972. doi: 10.1038/ nature 04082.

[23] Zeuzem S, Feinman SV, Rasenack J, Heathcote EJ, Lai MY, Gane E, et al. Peginterferon alfa-2a in patients with chronic hepatitis C. N Engl J Med 2000;343:1666-1672. doi: 10.1056/nejm200012073432301.

[24] Lindsay KL, Trepo C, Heintges T, Shiffman ML, Gordon SC, Hoefs JC, et al. A randomized, double-blind trial comparing pegylated interferon alfa-2b to interferon alfa-2b as initial treatment for chronic hepatitis C. Hepatology 2001;34:395-403. doi: 10.1053/jhep.2001.26371.

[25] Serranti D, Indolfi G, Resti M. New treatments for chronic hepatitis C: an overview for paediatricians. World J Gastroenterol 2014;20:15965-15974. doi: $10.3748 /$ wjg.v20.i43.15965.

[26] Schwarz KB, Gonzalez-Peralta RP, Murray KF, Molleston JP, Haber BA, Jonas $M M$, et al. The combination of ribavirin and peginterferon is superior to peginterferon and placebo for children and adolescents with chronic hepatitis C. Gastroenterology 2011;140:450-458.e1. doi: 10.1053/j.gastro.2010.10. 047.

[27] McHutchison JG, Gordon SC, Schiff ER, Shiffman ML, Lee WM, Rustgi VK, et $a$. Interferon alfa-2b alone or in combination with ribavirin as initial treatment for chronic hepatitis C. Hepatitis Interventional Therapy Group. N Engl J Med 1998;339:1485-1492. doi: 10.1056/NEJM199811193392101.

[28] Poynard T, Marcellin P, Lee SS, Niederau C, Minuk GS, Ideo G, et al. Randomised trial of interferon alpha2b plus ribavirin for 48 weeks or for 24 weeks versus interferon alpha2b plus placebo for 48 weeks for treatment of chronic infection with hepatitis $\mathrm{C}$ virus. International Hepatitis Interventional Therapy Group (IHIT). Lancet 1998;352:1426-1432.

[29] Druyts E, Thorlund K, Wu P, Kanters S, Yaya S, Cooper CL, et al. Efficacy and safety of pegylated interferon alfa-2a or alfa-2b plus ribavirin for the treatment of chronic hepatitis $C$ in children and adolescents: a systematic review and meta-analysis. Clin Infect Dis 2013;56:961-967. doi: 10.1093/cid/ cis1031.

[30] Wirth S, Ribes-Koninckx C, Calzado MA, Bortolotti F, Zancan L, Jara P, et al. High sustained virologic response rates in children with chronic hepatitis $C$ receiving peginterferon alfa-2b plus ribavirin. J Hepatol 2010;52:501-507. doi: 10.1016/j.jhep.2010.01.016.

[31] Ge D, Fellay J, Thompson AJ, Simon JS, Shianna KV, Urban TJ, et al. Genetic variation in IL28B predicts hepatitis C treatment-induced viral clearance. Nature 2009;461:399-401. doi: 10.1038/nature08309.

[32] Domagalski K, Pawłowska M, Tretyn A, Halota W, Pilarczyk M, Smukalska E, et al. Impact of IL-28B polymorphisms on pegylated interferon plus ribavirin treatment response in children and adolescents infected with HCV genotypes 1 and 4. Eur J Clin Microbiol Infect Dis 2013;32:745-754. doi: 10.1007/ s10096-012-1799-z.

[33] Wirth S, Pieper-Boustani H, Lang T, Ballauff A, Kullmer U, Gerner P, et al. Peginterferon alfa-2b plus ribavirin treatment in children and adolescents with chronic hepatitis C. Hepatology 2005;41:1013-1018. doi: 10.1002/ hep. 20661.

[34] Sung $H$, Chang M, Saab S. Management of hepatitis $C$ antiviral therapy adverse effects. Curr Hepat Rep 2011;10:33-40. doi: 10.1007/s11901010-0078-7.

[35] Mehta N, Murthy UK, Kaul V, Alpert S, Abruzzese G, Teitelbaum C. Outcome of retinopathy in chronic hepatitis $C$ patients treated with peginterferon and ribavirin. Dig Dis Sci 2010;55:452-457. doi: 10.1007/s10620-009-0721-8.

[36] Veluru C, Atluri D, Chadalavada R, Burns E, Mullen KD. Skin rash during chronic hepatitis C therapy. Gastroenterol Hepatol (N Y) 2010;6:323-325.

[37] Ward RP, Kugelmas $M$. Using pegylated interferon and ribavirin to treat patients with chronic hepatitis C. Am Fam Physician 2005;72:655-662.

[38] Kanda T, Steele R, Ray R, Ray RB. Small interfering RNA targeted to hepatitis C virus $5^{\prime}$ nontranslated region exerts potent antiviral effect. J Virol 2007;81: 669-676. doi: 10.1128/JVI.01496-06.

[39] Moradpour D, Penin F. Hepatitis C virus proteins: from structure to function. Curr Top Microbiol Immunol 2013;369:113-142. doi: 10.1007/978-3-64227340-7_5.

[40] Morikawa K, Lange CM, Gouttenoire J, Meylan E, Brass V, Penin F, et al. Nonstructural protein 3-4A: the Swiss army knife of hepatitis $C$ virus. J Viral Hepat 2011;18:305-315. doi: 10.1111/j.1365-2893.2011.01451.x.

[41] Jacobson IM, McHutchison JG, Dusheiko G, Di Bisceglie AM, Reddy KR, Bzowej $\mathrm{NH}$, et al. Telaprevir for previously untreated chronic hepatitis $\mathrm{C}$ virus infection. N Engl J Med 2011;364:2405-2416. doi: 10.1056/NEJMoa1012912.

[42] Poordad F, McCone J Jr, Bacon BR, Bruno S, Manns MP, Sulkowski MS, et al. Boceprevir for untreated chronic HCV genotype 1 infection. N Engl J Med 2011;364:1195-1206. doi: 10.1056/NEJMoa1010494.

[43] Wyles DL. Beyond telaprevir and boceprevir: resistance and new agents for hepatitis C virus infection. Top Antivir Med 2012;20:139-145.
[44] HCV guidance: recommendations for testing, managing, and treating hepatitis C. Available from: http://www.hcvguidelines.org.

[45] Kohler J], Nettles JH, Amblard F, Hurwitz SJ, Bassit L, Stanton RA, et al. Approaches to hepatitis $C$ treatment and cure using NS5A inhibitors. Infect Drug Resist 2014;7:41-56. doi: 10.2147/IDR.S36247.

[46] Fridell RA, Qiu D, Valera L, Wang C, Rose RE, Gao M. Distinct functions of NS5A in hepatitis $C$ virus RNA replication uncovered by studies with the NS5A inhibitor BMS-790052. J Virol 2011;85:7312-7320. doi: 10.1128/JVI. 00253-11.

[47] Nettles RE, Gao M, Bifano M, Chung E, Persson A, Marbury TC, et al. Multiple ascending dose study of BMS-790052, a nonstructural protein $5 \mathrm{~A}$ replication complex inhibitor, in patients infected with hepatitis $C$ virus genotype 1 . Hepatology 2011;54:1956-1965. doi: 10.1002/hep.24609.

[48] Lee C. Daclatasvir: potential role in hepatitis C. Drug Des Devel Ther 2013;7: 1223-1233. doi: 10.2147/DDDT.S40310.

[49] U.S. Food and Drug Administration approves Gilead's Epclusa ${ }^{\circledR}$ (Sofosbuvir/Velpatasvir) for the treatment of all genotypes of chronic hepatitis C. Available from: http://www.gilead.com/news/press-releases/2016/6/us-foodand-drug-administration-approves-gileads-epclusa-sofosbuvirvelpatasvirfor-the-treatment-of-all-genotypes-of-chronic-hepatitis-c, accessed June 2016.

[50] Koch U, Narjes F. Allosteric inhibition of the hepatitis C virus NS5B RNA dependent RNA polymerase. Infect Disord Drug Targets 2006;6:31-41.

[51] Wagner F, Thompson R, Kantaridis C, Simpson P, Troke PJ, Jagannatha S, et al. Antiviral activity of the hepatitis $C$ virus polymerase inhibitor filibuvir in genotype 1-infected patients. Hepatology 2011;54:50-59. doi: 10.1002/ hep. 24342.

[52] Larrey D, Lohse AW, de Ledinghen V, Trepo C, Gerlach T, Zarski JP, et al. Rapid and strong antiviral activity of the non-nucleosidic NS5B polymerase inhibitor BI 207127 in combination with peginterferon alfa $2 a$ and ribavirin. J Hepatol 2012;57:39-46. doi: 10.1016/j.jhep.2012.02.015.

[53] Pockros PJ. Drugs in development for chronic hepatitis C: a promising future. Expert Opin Biol Ther 2011;11:1611-1622. doi: 10.1517/14712598.2011. 627851.

[54] Herbst DA Jr, Reddy KR. Sofosbuvir, a nucleotide polymerase inhibitor, for the treatment of chronic hepatitis $C$ virus infection. Expert Opin Investig Drugs 2013;22:527-536. doi: 10.1517/13543784.2013.775246.

[55] AASLD/IDSA HCV Guidance Panel. Hepatitis C guidance: AASLD-IDSA recommendations for testing, managing, and treating adults infected with hepatitis C virus. Hepatology 2015;62:932-954. doi: 10.1002/hep.27950.

[56] Bourlière M, Gordon SC, Ramji A, Ravendhran N, Tran T, Hyland RH, et al. Sofosbuvir/Velpatasvir/Voxilaprevir for 12 weeks as a Salvage regimen in NS5A inhibitor-experienced patients with genotype 1-6 infection: the phase 3 POLARIS-1 study. The Liver Meeting, Boston, MA, 2016.

[57] Jacobson IM, Asselah T, Nahass R, Bhandari BR, Tran A, Hyland RH, et al. A randomized phase 3 trial of Sofosbuvir/Velpatasvir/Voxilaprevir for 8 weeks compared to Sofosbuvir/Velpatasvir for 12 weeks in DAA-naïve genotype 1-6 HCV infected patients: the POLARIS-2 study. The Liver Meeting, Boston, MA, 2016.

[58] Foster GR, Thompson A, Ruane PJ, Borgia S, Dore G, Workowski K, et al. A randomized, phase 3 trial of Sofosbuvir/Velpatasvir/Voxilaprevir for 8 weeks and Sofosbuvir/Velpatasvir for 12 weeks for patients with genotype $3 \mathrm{HCV}$ infection and cirrhosis: the POLARIS-3 study. The Liver Meeting, Boston, MA, 2016.

[59] Zeuzem S, Flamm SL, Tong M, Vierling JM, Pianko S, Buggisch P, et al. A randomized, controlled, phase 3 trial of sofosbuvir/velpatasvir/voxilaprevir or sofosbuvir/velpatasvir for 12 weeks in direct-acting antiviral-experienced patients with genotype 1-6 HCV infection: the POLARIS-4 study. The Liver Meeting, Boston, MA, 2016

[60] Gane E, Lawitz E, Pugatch D, Papatheodoridis G, Brau N, Brown A, et al. EXPEDITION-4: efficacy and safety of glecaprevir/pibrentasvir (ABT493/ABT-530) in patients with renal impairment and chronic hepatitis C virus genotype 1-6 infection. The Liver Meeting, Boston, MA, 2016.

[61] Asselah T, Hezode C, Zadeikis N, Elkhashab M, Colombo M, Marinho R, et al. ENDURANCE-4: efficacy and safety of glecaprevir/pibrentasvir (formerly ABT-494/ABT-530) treatment in patients with chronic HCV genotype 4, 5, or 6 infection. The Liver Meeting, Boston, MA, 2016.

[62] Hassanein T, Wyles D, Wang S, Kwo PY, Shiff ML, Younes Z, et al. SURVEYORII, part 4: glecaprevir/pibrentasvir [ABT493+ABT530] demonstrates high SVR rates in patients with HCV genotype $2,4,5$, or 6 infection without cirrhosis following an 8-week treatment duration. The Liver Meeting, Boston, MA, 2016.

[63] Zeuzem S, Feld J, Wang S, Bourliere M, Wedemeyer H, Gane E, et al. ENDURANCE-1: a phase 3 evaluation of the efficacy and safety of 8- versus 12-week treatment with glecaprevir/pibrentasvir (formerly ABT-493/ABT530 ) in HCV genotype 1 infected patients with or without HIV-1 co-infection and without cirrhosis. The Liver Meeting, Boston, MA, 2016.

[64] Wyles D, Poordad F, Wang S, Alric L, Felizarta F, Kwo PY, et al. SURVEYOR-II, part 3: efficacy and safety of glecaprevir/pibrentasvir (ABT-493/ABT-530) in 
Yang C.H.T. et al: Therapies for chronic hepatitis C in children

patients with hepatitis $C$ virus genotype 3 infection with prior treatment experience and/or cirrhosis. The Liver Meeting, Boston, MA, 2016.

[65] Kowdley KV, Colombo M, Zadeikis N, Mantry PS, Calinas F, Aguilar H, et al. ENDURANCE-2: safety and efficacy of glecaprevir/pibrentasvir in hepatitis C virus genotype 2-infected patients without cirrhosis: a randomized, doubleblind, placebo-controlled study. The Liver Meeting, Boston, MA, 2016.

[66] Wyles D, Wedemeyer H, Reddy KR, Luetkemeyer A, Jacobson I, Vierling J, et al. Safety and efficacy of the fixed-dose combination regimen of MK3682/grazoprevir/MK-8408 (ruzasvir) in cirrhotic or non-cirrhotic patients with chronic HCV GT1 infection who previously failed a direct-acting antiviral regimen (C-SURGE). The Liver Meeting, Boston, MA, 2016.

[67] Serfaty L, Pianko S, Ari ZB, Laursen AL, Hansen J, Gane EJ, et al. High sustained virologic response rates in patients with chronic HCV GT1, 2 or 3 infection following 16 weeks of MK-3682/grazoprevir/MK-8408 (ruzasvir) plus ribavirin after failure of 8 weeks of therapy (part C of C-CREST-1 \& 2). The Liver Meeting, Boston, MA, 2016.

[68] Lawitz E, Yoshida EM, Buti M, Vierling JM, Almasio PL, Bruno S, et al. Safety and efficacy of the fixed-dose combination regimen of MK-3682/grazoprevir/MK-8408 (ruzasvir) with or without ribavirin in non-cirrhotic or cirrhotic patients with chronic HCV GT1, 2 or 3 infection (part B of C-CREST-1 \& 2). The Liver Meeting, Boston, MA, 2016.

[69] Fischler B, Priftakis P, Sundin M. Sofosbuvir and simeprevir treatment of a stem cell transplanted teenager with chronic hepatitis $\mathrm{C}$ infection. Pediatr Infect Dis J 2016;35:708-710. doi: 10.1097/INF.0000000000001122.

[70] Thomas P, Santiago T, Dallas MH. Treatment of hepatitis $C$ in a pediatric patient using simeprevir and sofosbuvir immediately after an umbilical cord blood transplantation. Bone Marrow Transplant 2016;51:735-737. doi: 10. 1038/bmt.2015.309

[71] Smith SK, Rosenthal P. Clearance of hepatitis C virus after fixed-dose combination ledipasvir/sofosbuvir in an adolescent female with decompensated cirrhosis. J Pediatr Gastroenterol Nutr 2016;63:516-517. doi: 10.1097/ MPG.0000000000001278.

[72] Garrison KL, Mathias A, Kersey K, Kanwar B, Ni L, Jain A, et al. Pharmacokinetics of once-daily sofosbuvir and ledipasvir/sofosbuvir in $\mathrm{HCV}$-infected pediatrics aged 6 to $<12$ years old. The Liver Meeting, Boston, MA, 2016.

[73] Kirby B. Adult doses of sofosbuvir plus ribavirin or ledipasvir/sofosbuvir provided comparable plasma exposures and tolerable safety profile in adolescents with hepatitis $\mathrm{C}$ virus (HCV) infection. San Francisco, CA: American Association for the Study of Liver Disease Annual Meeting, 2015.

[74] Schwarz KB. Sofosbuvir + ribavirin for 12 or 24 weeks is safe and effective in adolescents with genotype 2 or genotype 3 chronic hepatitis $C$ infection. The Liver Meeting, Boston, MA, 2016.

[75] Schwarz KB. Late breaker oral session (LB-4597). Barcelona, Spain: European Association for the Study of the Liver, 2016.

[76] Younossi ZM. Significant QoL improvement with LDV/SOF in adolescents with HCV GT1. The Liver Meeting, Boston, MA, 2016.

[77] Balistreri W, Rosenthal P, Bansal S, Gonzalez-Peralta R, Wen J, Whitworth MS, et al. Ledipasvir/sofosbuvir (LDV/SOF) for 12 weeks is safe and effective in adolescents with chronic hepatitis C infection. J Pediatr Gastroenterol Nutr 2016;63:S140-141. 